\title{
A Variant of Glanzmann's Thrombasthenia with Abnormal Glycoprotein Ilb-IIla Complexes in the Platelet Membrane
}

\author{
Alan T. Nurden, Jean-Philippe Rosa, Dominique Foumier, Chantal Legrand, Dominique Didry, \\ Armelle Parquet, and Dominique Pidard \\ Unité 150, Institut National de la Santé et de la Recherche Médicale, and Unité Associé 334, Centre National de la Recherche \\ Scientifique, Hôpital Lariboisière, 75475 Paris Cedex 10; and Centre Régional de Transfusion Sanguine, Lille, France
}

\begin{abstract}
Patient C.M. presented platelet function defects symptomatic of Glanzmann's thrombasthenia. However, analysis of surface-labeled platelets by SDS-polyacrylamide gel electrophoresis revealed the usual presence of the major glycoproteins, including GP IIb and GP IIIa. Platelet fibrinogen was not detected. Analysis of Triton X-100 extracts of $\mathrm{Ca}^{2+}$-washed C.M. platelets by crossed immunoelectrophoresis (CIE) showed normal amounts of GP IIb-IIIa complexes. However, when samples were electrophoresed through an agarose gel containing ${ }^{125} \mathrm{I}$-fibrinogen, the usual binding of fibrinogen to GP IIb-IIIa did not occur. Furthermore, the GP IIb-IIIa complexes showed an increased sensitivity to dissociation with EDTA, either after Triton X-100 solubilization or in the intact platelet membrane. For example, after incubation with EDTA at room temperature, the patient's platelets bound little of the monoclonal antibodies AP-2 or T10 (anti-GP IIb-IIIa complex) although normally binding Tab (anti-GP IIb). Patient C.M. appears to represent a subgroup of thrombasthenia where platelets contain unstable GP IIb-IIIa complexes unable to support fibrinogen binding.
\end{abstract}

\section{Introduction}

Glanzmann's thrombasthenia is a rare blood disorder characterized; in vitro, by the absence of platelet aggregation in response to ADP and other physiologic agonists $(1,2)$. Numerous studies suggest that the hemorrhagic tendency arises from the inability of the platelets to adhere one with another after activation, with the result that thrombus formation does not occur (reviewed in reference 3). In most patients, platelets are also unable to support clot retraction.

In 1974, Nurden and Caen described glycoprotein (GP) ${ }^{1} \mathrm{ab}-$ normalities when membrane fractions isolated from the platelets of three patients were analyzed by SDS-polyacrylamide gel electrophoresis (SDS-PAGE) (4). It is now generally recognized that

A preliminary report of part of this study has appeared in abstract form (1983, Thromb. Haemostasis, 50:216a). Address correspondence to Dr. Nurden, U-150 INSERM, Hôpital Lariboisière, 6 rue Guy Patin, 75475 Paris Cedex 10, France.

$$
\text { Received for publication } 25 \text { August } 1986 .
$$

1. Abbreviations used in this paper: $\mathrm{ACD}$, acid citrate dextrose; $\mathrm{CB}-\mathrm{R}$, Coomassie Blue R-250; CIE, crossed immunoelectrophoresis; GP, glycoprotein; PRP, platelet-rich plasma.

J. Clin. Invest.

(c) The American Society for Clinical Investigation, Inc. 0021-9738/87/03/0962/08 \$1.00

Volume 79, March 1987, 962-969 a major lesion of thrombasthenic platelets is the absence, or severe reduction in concentration, of membrane GP IIb and GP IIIa (3, 5-8). Platelet fibrinogen is also often absent or decreased. The finding that fibrinogen binding to ADP-stimulated thrombasthenic platelets was defective (9-12) was initial evidence that the missing GPs might constitute part of the platelet fibrinogen receptor. When solubilized from platelet membranes with nonionic detergent, GP IIb and GP IIIa are present as divalent cationmediated heterodimer complexes $(13,14)$. A number of monoclonal antibodies have been prepared that recognize determinants on GP IIb-IIIa (15); with some, the binding sites are lost after divalent cation chelation and GP IIb-IIIa dissociation. Two such antibodies are AP-2 (16) and T10 (17). An extensive binding of these antibodies to unstimulated platelets implies that IIb-IIIa heterodimers are a normal constituent of the circulating platelet membrane. Thus, thrombasthenia may be seen essentially as a disorder of the GP IIb-IIIa complexes.

Functional heterogeneity in Glanzmann's thrombasthenia was first noted by Caen (2) who proposed two patient subgroups, with the rare type II patients differing from those with type I disease in that their platelets were able to support a modified clot retraction and possessed appreciable amounts of platelet fibrinogen. Subsequent studies using crossed immunoelectrophoresis (CIE) revealed that platelets of the type I patients lacked, or merely contained trace amounts of GP IIb-IIIa complexes $(6,8,18,19)$, whereas platelets of patients in the type II subgroup contained more of these GPs $(6,19)$. Recent preliminary reports have also described patients with at least $50 \%$ of the normal content of GP IIb and GP IIIa in their platelets, while exhibiting all of the clinical and platelet function abnormalities typical of Glanzmann's thrombasthenia (20-23). We now describe studies on one such patient whose platelets contain GP IIb-IIIa complexes that are unusually susceptible to dissociation by EDTA and that are unable to support fibrinogen binding. It is proposed that the patient represents a new variant or subgroup of the disease.

\section{Methods}

Subjects. The patient (C.M.) was referred to us as a typical case of type I Glanzmann's thrombasthenia $(1,2)$. A white female now 24 yr old, she has experienced bleeding since birth. The first major event occurred after a fall when she was 2 yr old. Bleeding episodes have since continued at irregular intervals, and have featured severe epistaxis, spontaneous gingival bleeding, and hemorrhagia. Although she has received blood transfusions on several occasions, tests for anti-platelet antibodies have always been negative. The patient has been examined by us on four occasions over $5 \mathrm{yr}$. Her platelet count was normal, $2 \times 10^{8}$ platelets/ $\mathrm{ml}$ at the last time of study. White cell and red cell counts were also normal. The Duke bleeding time was prolonged (>10 min). Ristocetininduced platelet aggregation was normal in both patient and control plasma, other platelet function studies are described in the text. Routine 
tests showed no plasma or coagulation factor abnormalities. There is no family history of a bleeding disorder and platelet function of both parents was normal. Consanguinity has been excluded. Control donors were adult volunteers from hospital staff.

Platelet function testing. Platelet aggregation in citrated platelet-rich plasma (PRP) was studied in a Payton platelet aggregometer (Payton Scientific Inc., Buffalo, NY) using standard procedures. Washed platelets were prepared from acid citrate dextrose (ACD) anticoagulated blood using the buffer systems of Patscheke (24) as adapted by Legrand et al. (25). The platelets were finally resuspended in a modified Tyrode buffer (Tyrode- $\mathrm{Ca}^{2+}$ ) which consisted of $137 \mathrm{mM} \mathrm{NaCl}, 3 \mathrm{mM} \mathrm{KCl}, 12 \mathrm{mM}$ $\mathrm{NaHCO}_{3}, 0.3 \mathrm{mM} \mathrm{NaH}_{2} \mathrm{PO}_{4} 2 \mathrm{H}_{2} \mathrm{O}, 2 \mathrm{mM} \mathrm{CaCl}, 1 \mathrm{mM} \mathrm{MgCl}_{2}, 5.5$ $\mathrm{mM}$ glucose, $5 \mathrm{mM}$ Hepes (pH 7.4), and $0.35 \% \mathrm{wt} / \mathrm{vol}$ bovine serum albumin (BSA). On occasion, platelets were prelabeled by incubating the PRP with $0.6 \mu \mathrm{M}\left[{ }^{14} \mathrm{C}\right]$ serotonin $(40 \mathrm{mCi} / \mathrm{mmol}$; Radiochemical Centre, Amersham, England) for $30 \mathrm{~min}$ at $37^{\circ} \mathrm{C}$. Aggregation was studied at $37^{\circ} \mathrm{C}$ with constant stirring $(1,100 \mathrm{rpm})$ using samples adjusted to 3 $\times 10^{8}$ platelets $/ \mathrm{ml}$. Stimuli used included 1-10 $\mu$ M ADP (disodium salt; Sigma Chemical Co., St. Louis, MO) in the presence of $200 \mu \mathrm{g} / \mathrm{ml}$ dialysed human fibrinogen (Kabi Diagnostics, Stockholm, Sweden), 12.5-50.0 $\mu \mathrm{g} / \mathrm{ml}$ polymerized type I calf skin collagen (from Dr. Y. Legrand, Hôpital Saint-Louis, Paris) and 0.05-1.00 U/ml human $\alpha$-thrombin (from Dr. M. C. Guillin, Faculté Bichat, Paris). The purity of the collagen preparation has been previously assessed (25) while the purified human $\alpha$ thrombin had an activity of $3,000 \mathrm{NIH} \mathrm{U/ml} \mathrm{protein.} \mathrm{Samples} \mathrm{were}$ taken after $3 \mathrm{~min}$ for $\left[{ }^{14} \mathrm{C}\right]$ serotonin release $(25)$. Clot retraction was studied by incubating $1 \mathrm{ml}$ of citrated PRP, diluted twice with $0.15 \mathrm{M}$ $\mathrm{NaCl}$, with $0.5 \mathrm{U}$ thrombin in glass tubes at $37^{\circ} \mathrm{C}$ for $1 \mathrm{~h}$.

Fibrinogen binding to stimulated platelets. Fibrinogen binding to ADP- or collagen-stimulated platelets was studied as previously described by us $(25,26)$. Briefly, washed platelets at $6 \times 10^{8} / \mathrm{ml}$, prepared as given above, were mixed with upwards of $20 \mu \mathrm{g} / \mathrm{ml}$ [ [25I]fibrinogen followed by $10 \mu \mathrm{M}$ ADP or $50 \mu \mathrm{g} / \mathrm{ml}$ collagen. Incubation was continued without agitation (ADP) or with stirring at $200 \mathrm{rpm}$ (collagen) (see reference 26) for up to $30 \mathrm{~min}$ at room temperature. At selected times, duplicate samples were removed and the platelets sedimented through a dibutylphthalate and dioctylphthalate (1:1 vol/vol) oil layer. Platelet-associated radioactivity was measured in a gamma counter (model 7,000; Beckman Instruments, Inc., Gagny, France). Nonspecific binding was determined by performing parallel incubations in the absence of added ADP or collagen. This amounted to $<15 \%$ of the total binding. Results are given as the specific binding, which was calculated by subtracting the nonspecific from the total binding. The ${ }^{125}$ I-fibrinogen preparation used in these experiments had a specific activity of $40 \mu \mathrm{Ci} / \mathrm{mg}$ protein, its characterization has been detailed previously (25).

Radiolabeling of platelet membrane glycoproteins. Here, blood was taken into EDTA anticoagulant and platelets isolated according to the procedures of Nurden et al. (27). The platelets were washed three times in $10 \mathrm{mM}$ Tris- $\mathrm{HCl}, 0.15 \mathrm{M} \mathrm{NaCl}, 5 \mathrm{mM}$ glucose, and $1 \mathrm{mM}$ EDTA (pH 7.4) (Tris-EDTA). Lactoperoxidase-catalyzed ${ }^{125} \mathrm{I}$-labeling of the platelet surface proteins was then performed as previously described $(27,28)$. The labeling procedures for incorporating ${ }^{3} \mathrm{H}$ into the surface exposed carbohydrate chains of platelet membrane glycoproteins were those of Nurden et al. (28). Briefly, washed control and patient platelets suspended at $10^{9} / \mathrm{ml}$ in phosphate-buffered saline $(\mathrm{pH} 7.4)$ were incubated sequentially with neuraminidase, galactose oxidase, and sodium $\left[{ }^{3} \mathrm{H}\right]$ borohydride; or galactose oxidase and sodium $\left[{ }^{3} \mathrm{H}\right]$ borohydride alone.

One-dimensional SDS-PAGE. Washed, unlabeled, ${ }^{125} \mathrm{I}$-labeled or ${ }^{3} \mathrm{H}-$ labeled platelets were resuspended at $2 \times 10^{9}$ platelets $/ \mathrm{ml}$ in $10 \mathrm{mM}$ Tris- $\mathrm{HCl}, 0.15 \mathrm{M} \mathrm{NaCl}$, and $5 \mathrm{mM} \mathrm{N}$-ethylmaleimide (pH 7.0). A 1/5vol of $12 \%$ (wt/vol) SDS was added and the samples solubilized by heating at $100^{\circ} \mathrm{C}$ for $5 \mathrm{~min}$. When performed, disulfides were reduced by incubating SDS-soluble extracts at $37^{\circ} \mathrm{C}$ for $1 \mathrm{~h}$ with $5 \%$ (vol/vol) 2-mercaptoethanol. Samples were electrophoresed on 7-12 or 7-20\% gradient acrylamide slab gels as detailed previously $(27,28)$. Proteins were located by Coomassie Blue R-250 (CB-R) staining, ${ }^{125}$ I-labeled proteins on dried gels by autoradiography (27) and ${ }^{3} \mathrm{H}$-labeled proteins by fluorography (28).
High resolution two-dimensional acrylamide gel electrophoresis. Suspensions of ${ }^{125}$ I-labeled platelets were prepared and solubilized with SDS as described above. Nonreduced samples (200 $\mu \mathrm{g}$ protein) were made $9 \mathrm{M}$ with urea and $8 \%$ (vol/vol) with Triton X-100. Isoelectric focusing on $4 \%$ acrylamide rod gels was performed according to the procedure of Ames and Nikaido (29). After the first-dimension separation, individual gels were incubated for $1 \mathrm{~h}$ at room temperature in $2 \%$ SDS and 5\% 2-mercaptoethanol before being placed onto 7-12\% gradient acrylamide slab gels. The second-dimension electrophoresis was then performed as previously described by us for the two-dimensional nonreduced/reduced system of SDS-PAGE (27). Protein was detected by CB-R staining and ${ }^{125}$ I-labeled glycoproteins by autoradiography.

$C I E$. Initial experiments were performed on platelets isolated from EDTA-anticoagulated blood and washed in Tris-EDTA (see Results). In subsequent studies, blood was anticoagulated with ACD and platelets isolated as described in "Platelet Function Testing." Here, platelets were washed in (a) $36 \mathrm{mM}$ citric acid, $5 \mathrm{mM}$ glucose, $5 \mathrm{mM} \mathrm{KCl}, 2 \mathrm{mM}$ $\mathrm{CaCl}_{2}, 1 \mathrm{mM} \mathrm{MgCl}, 103 \mathrm{mM} \mathrm{NaCl}, 3.5 \mathrm{mg} / \mathrm{ml} \mathrm{BSA}, 100 \mathrm{nM}$ PGE 1 , and $25 \mu \mathrm{g} / \mathrm{ml}$ apyrase (pH 6.5) (buffer A) (25), or (b) in the same buffer at $\mathrm{pH} 7.4$ but with the divalent cations omitted and replaced by $1 \mathrm{mM}$ EDTA. The $\mathrm{pH}$ was raised to $\mathrm{pH} 7.4$ to maintain the chelating capacity of the EDTA.

Platelets washed by either method were resuspended at $6 \times 10^{9} / \mathrm{ml}$ in $0.038 \mathrm{M}$ Tris- $\mathrm{HCl}$ and $0.1 \mathrm{M}$ glycine (pH 8.7) (Tris-glycine) and solubilized at $4^{\circ} \mathrm{C}$ by addition of a $1 / 10 \mathrm{vol}$ of $10 \%$ (vol/vol) Triton X-100 in Tris-glycine $(6,8)$. On occasion, solubilization was performed in the additional presence of a cocktail of protease inhibitors consisting of 0.5 $\mathrm{mg} / \mathrm{ml}$ leupeptin (Sigma Chemical Co., St. Louis, MO), $1 \mathrm{mM}$ phenylmethylsulfonyl fluoride, $10 \mathrm{mM}$ benzamidine, and $100 \mu \mathrm{g} / \mathrm{ml}$ soybean trypsin inhibitor. CIE of the Triton X-100-soluble extracts was performed according to our previously described procedures with trace amounts of ${ }^{125}$ I-labeled monoclonal antibodies (detailed below) in the intermediate gel and the isolated IgG of a rabbit anti-whole platelet antiserum in the superior gel $(13,16,17)$. In some experiments, small amounts of ${ }^{125} \mathrm{I}$ fibrinogen (specific activity in the range $50-200 \mathrm{cpm} / \mathrm{ng}$ protein) were incorporated into the intermediate gel and the binding of fibrinogen to GP IIb-IIla complexes studied. For these experiments, anti-fibrinogen antibodies were first removed from the rabbit anti-human platelet antibody preparation by passing the immunoglobulins across an affinity column prepared by coupling fibrinogen to $\mathrm{CNBr}$-activated Sepharose 4B (Pharmacia Fine Chemicals Div., Pharmacia Inc., Uppsala, Sweden) according to the manufacturer's instructions. Further details of the amounts of radiolabeled monoclonal antibody or fibrinogen in the intermediate gel are given in the figure legends. Immunoprecipitates were revealed by CB-R staining and those containing antigens reactive with radiolabeled proteins by autoradiography.

Direct binding of ${ }^{125}$ I-labeled monoclonal antibodies to platelets. Three antibodies were used in these experiments. Table I summarizes their characteristics. AP-2 was kindly made available by Drs. R. Montgomery and T. Kunicki (Blood Center of Southeastern Wisconsin, Milwaukee, WI). T10 and Tab were generously provided by Dr. R. McEver (University of Texas Health Science Center, San Antonio, TX). Samples ( 0.5 $\mathrm{mg}$ ) of isolated IgG were radiolabeled with ${ }^{125}$ I using the chloramine T Method (16). Free ${ }^{125}$ I was separated from the radiolabeled IgG by gel filtration through a Sephadex G25 column (Pharmacia Fine Chemicals Div., Pharmacia Inc.). Specific activities of the labeled antibodies ranged from 200 to $700 \mathrm{cpm} / \mathrm{ng}$ protein. Binding of the labeled antibodies to platelets was measured using the procedure of Pidard et al. (16) with slight modifications. Platelets were isolated from ACD anticoagulated blood and washed in buffer $A$ (see previous section). They were resuspended in Tyrode-Ca ${ }^{2+}$ or in the same buffer in which divalent cations were omitted and replaced by $1 \mathrm{mM}$ EDTA (Tyrode-EDTA). Platelet concentrations were adjusted to $10^{8} / \mathrm{ml}$. Aliquots $(0.3 \mathrm{ml})$ were incubated at room temperature for 30 min before being mixed with ${ }^{125}$ I-antibody $(0.5-5.0 \mu \mathrm{g} / \mathrm{ml})$ added in a total volume of $0.06 \mathrm{ml}$. After $30 \mathrm{~min}$ at room temperature, duplicate volumes $(0.16 \mathrm{ml})$ of each reaction mixture were layered over $0.5 \mathrm{ml}$ of $20 \%$ (wt/vol) sucrose dissolved in the appropriate platelet resuspension buffer. The platelets were separated by 
Table I. Some Characteristics of the Monoclonal Antibodies Used in this Study

\begin{tabular}{|c|c|c|c|c|c|}
\hline \multirow[b]{2}{*}{ Antibody } & \multirow{2}{*}{$\begin{array}{l}\text { Antigenic } \\
\text { determinant }\end{array}$} & \multicolumn{2}{|c|}{ Binding to washed platelets } & \multirow[b]{2}{*}{ Effect of EDTA } & \multirow[b]{2}{*}{ Reference } \\
\hline & & & $\mathbf{k D}$ & & \\
\hline & & No. of sites & $n M$ & & \\
\hline AP-2 & GP IIb-IIIa & $39,400 \pm 5,800$ & 0.81 & None & Pidard et al. (1986) \\
\hline T10 & GP IIb-IIIa & $50,600 \pm 5,600$ & 8.6 & $50-60 \%$ inhibition at $1 \mathrm{~h}$ & McEver et al. (1983) \\
\hline Tab & GP IIb & $47,800 \pm 11,200$ & 6.2 & None & McEver et al. (1983) \\
\hline
\end{tabular}

Data for the binding of ${ }^{125}$ I-labeled antibodies to washed platelets as given by the original authors. The effect of EDTA on antibody binding was studied at room temperature.

centrifugation at $12,000 \mathrm{~g}$ for $2 \mathrm{~min}$ (16). The radioactivities in both the pellet and supernatant were measured in a gamma counter (model 7,000; Beckman Instruments, Inc., Fullerton, CA). Nonspecific binding was assessed in parallel tubes in the presence of a 250:1 excess of unlabeled antibody. This value was subtracted from the total bound counts per minute to give the specific binding. Nonspecific binding amounted to $<2 \%$ of the total binding. Scatchard analysis was performed as described (16).

\section{Results}

Platelet function testing. Fig. 1 confirms that C.M. platelets in PRP did not aggregate with ADP. Further studies with PRP or washed platelet suspensions showed that the patient's platelets also failed to aggregate with collagen or thrombin at any of the doses tested (see Methods). In contrast, platelet shape change occurred normally. When tested with washed platelets, release of ${ }^{14} \mathrm{C}$-5HT from dense granules was normal with all but threshold amounts of collagen $(12.5 \mu \mathrm{g} / \mathrm{ml})$ and thrombin $(0.05$ $\mathrm{U} / \mathrm{ml}$ ) when little release was observed. Thrombin-induced clot retraction by C.M. platelets was markedly abnormal (Fig. 1). Whereas the clot in the control samples retracted within $10 \mathrm{~min}$, C.M. platelets failed to support retraction even after $1 \mathrm{~h}$ at $37^{\circ} \mathrm{C}$.

${ }^{125}$ I-fibrinogen binding to stimulated platelets. Fibrinogen binding to washed C.M. platelets was assessed in the presence of $10 \mu \mathrm{M}$ ADP and a range of ${ }^{125}$ I-fibrinogen concentrations.
Fig. 2 shows that no specific binding was observed, even under conditions where a saturation of receptors on control platelets was achieved. We have previously shown that normal human platelets washed according to the method used in the present study express $18,120 \pm 6,850$ sites for fibrinogen $(\mathrm{kD}=0.49 \pm 0.17$ $\mu \mathrm{M})$ after stimulation with $10 \mu \mathrm{M}$ ADP (25). The inability of ADP to induce fibrinogen receptor expression on C.M. platelets was confirmed on three separate occasions over a period of 2 yr. Once, fibrinogen binding was also studied over $30 \mathrm{~min}$ in the presence of $50 \mu \mathrm{g} / \mathrm{ml}$ collagen. Specific binding was $<10 \%$ of that which occurred to normal platelets (see reference 25) under the same conditions (data not shown).

Analysis of platelet proteins and GPs by one-dimensional $S D S-P A G E$ and two-dimensional acrylamide gel electrophoresis. Fig. 3 compares autoradiographs and CB-R-stained gels obtained after the analysis of ${ }^{125} \mathrm{I}$-labeled C.M. and control platelets. The respective autoradiographs are identical, with bands in the positions of GP IIb and GP IIIa dominant on the C.M. platelet pattern. CB-R staining confirmed the presence of GP IIb, this band being identified by its migration $\left(M_{\mathrm{r}}=142,000\right)$, and its absence from the pattern obtained for type I thrombasthenic platelets (see reference 3). GP IIIa co-migrates with other polypeptides under these conditions and could not be distinguished by CB-R staining. However, a severe reduction in the fibrinogen content of C.M. platelets was revealed. All other major polypeptides were normally detected. The above experiments were
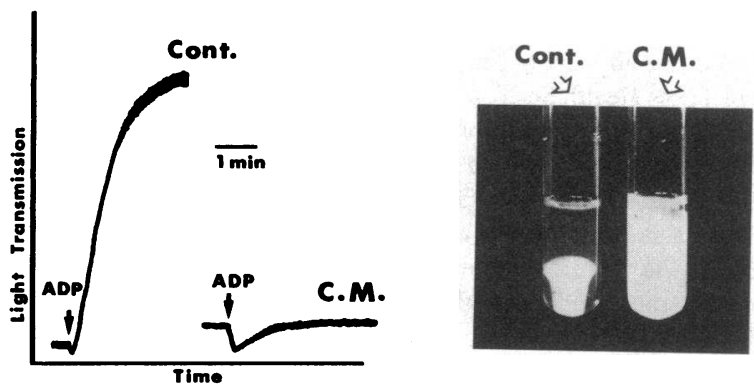

Platelet Aggregation

Figure 1. Abnormal function of C.M. platelets. Platelet aggregation was studied in citrated PRP $\left(3 \times 10^{8}\right.$ platelets $\left./ \mathrm{ml}\right)$ after addition of 10 $\mu \mathrm{M}$ ADP in a platelet aggregometer. Clot retraction was investigated by incubating diluted citrated PRP with $0.5 \mathrm{U}$ thrombin in glass tubes at $37^{\circ} \mathrm{C}$ for $1 \mathrm{~h}$. Cont., control.

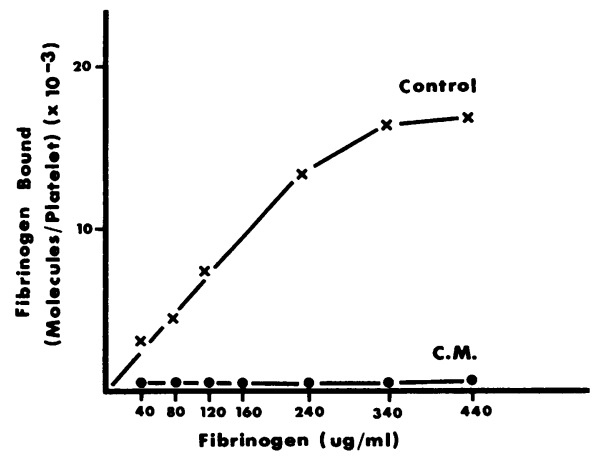

Figure 2. Fibrinogen-binding defect of C.M. platelets. Washed control and C.M. platelets $\left(5 \times 10^{8} / \mathrm{ml}\right)$ were incubated at room temperature in the presence of $10 \mu \mathrm{M}$ ADP and increasing amounts of ${ }^{125} \mathrm{I}$-fibrinogen. After $30 \mathrm{~min}$, the platelets were separated from the reaction mixture by centrifugation through oil. The total radioactivity in the pellet was measured and the specific binding of ${ }^{125} \mathrm{I}$-fibrinogen to the platelets was calculated (see Methods). Each point represents the mean of triplicate determinations. 

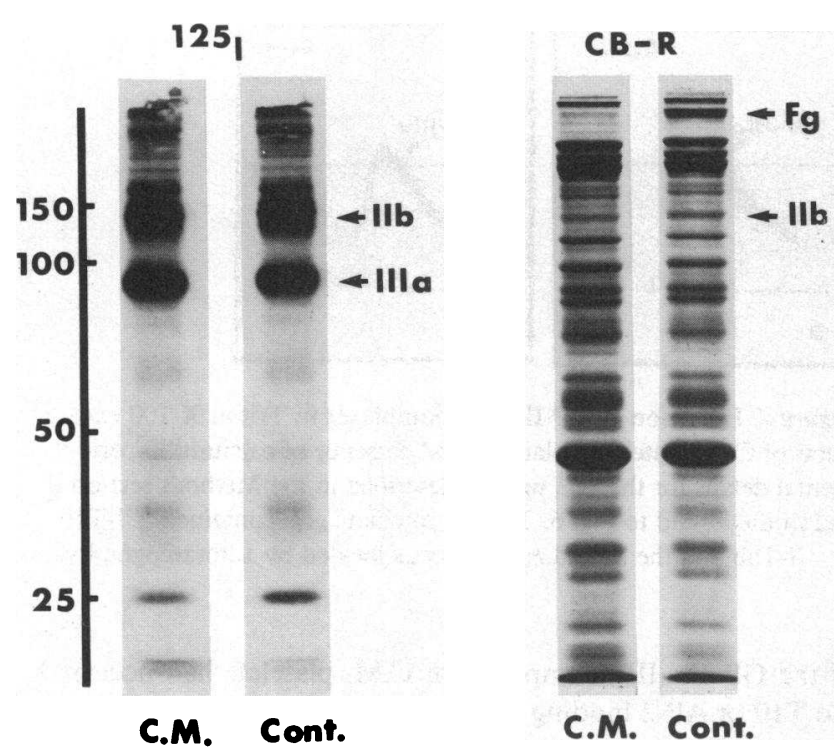

Figure 3. One-dimensional electrophoresis of the proteins and ${ }^{125} \mathrm{I}-\mathrm{la}-$ beled surface glycoproteins of C.M. and normal human platelets. Washed platelet suspensions were incubated with ${ }^{125} \mathrm{I}$ and the membrane glycoproteins labeled by the lactoperoxidase-catalyzed iodination procedure (see Methods). Samples (100 $\mu \mathrm{g}$ ) of nonreduced proteins were separated by SDS-PAGE on 7-12\% gradient acrylamide slab gels. Typical autoradiographs $\left({ }^{125} \mathrm{I}\right)$ and stained protein patterns (CB-R) are illustrated. $\mathrm{Fg}$, fibrinogen. Numbers at left, $M_{\mathrm{r}} \times 10^{-3}$.

repeated with platelets labeled with ${ }^{3} \mathrm{H}$ incorporated into the surface exposed carbohydrate chains of the membrane glycoproteins (see Methods). The labeling intensities of the major glycoproteins of control and C.M. platelets were compared by densitometric scanning after fluorography. The patterns were indistinguishable, and were similar to those previously described by us for normals (27). In particular, the analysis after disulfide reduction showed the usual presence of both the $\alpha$ - and $\beta$-subunits of GP IIb in C.M. platelets.

In a further attempt to uncover structural defects in GP IIb and/or GP IIIa, detergent-soluble extracts of ${ }^{125}$ I-labeled C.M. platelets were analyzed by high resolution two-dimensional gel electrophoresis incorporating isoelectric focusing in the first dimension. Fig. 4 reveals a normal migration and isoelectric point for GP IIb and GP IIIa of C.M. platelets.

$C I E$. Initial investigations were performed using platelets washed in Tris-EDTA as in our previous studies using this technique $(6,8,13,19)$ and in the SDS-PAGE experiments described above. Fig. 5 compares the autoradiographs obtained after the analysis of Triton X-100 extracts of ${ }^{125} \mathrm{I}$-labeled C.M. and control platelets. A striking decrease in the size of the GP IIb-IIIa precipitate was a marked feature of the C.M. platelet pattern. Additional precipitates in positions similar to those previously identified as containing dissociated GP IIb and GP IIIa (13) were clearly apparent. CB-R staining (not shown) revealed the decreased content of GP IIb-IIIa complexes but did not permit the detection of the additional precipitates, which were in part masked by others in this region of the gel. CB-R staining, however, confirmed the decreased fibrinogen content of C.M. platelets previously illustrated in Fig. 3. Performing the detergent solubilization in the presence of a cocktail of protease inhibitors (see Methods) did not restore the normal GP IIb-IIIa precipitate to the C.M. platelet pattern. Analysis of the Triton X-100-soluble
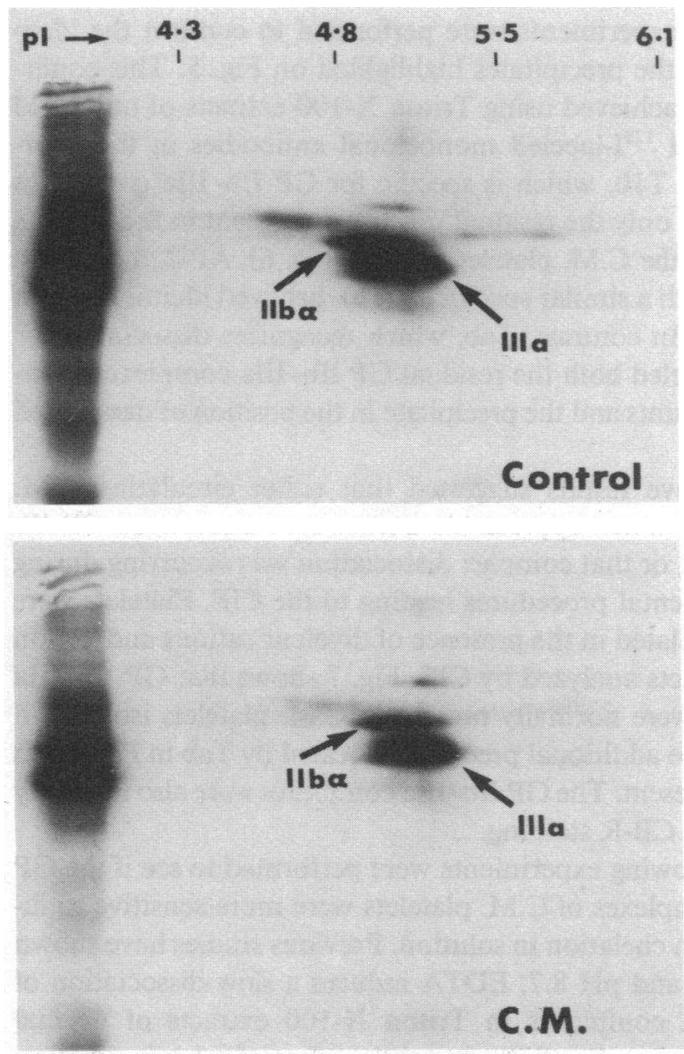

Figure 4. Two-dimensional electrophoresis of the ${ }^{125}$ I-labeled surface glycoproteins of C.M. and normal human platelets. SDS-soluble extracts ( $200 \mu \mathrm{g}$ protein) of radiolabeled platelets were made $9 \mathrm{M}$ with urea and Triton X-100 added to give a 4:1 ratio with respect to the SDS. After first-dimension separation by isoelectric focusing, the gels were incubated with $2 \%$ SDS and 5\% 2-mercaptoethanol during $1 \mathrm{~h}$ at room temperature. Second-dimension separation of the reduced proteins was by SDS-PAGE using 7-12\% gradient acrylamide slab gels. Typical autoradiographs obtained from dried CB-R-stained slab gels are illustrated. Only those areas of the autoradiographs that show the major membrane glycoproteins are shown.

and insoluble fractions of C.M. platelets by SDS-PAGE showed a usual $>90 \%$ solubilization of GP IIb and GP IIIa by the nonionic detergent.

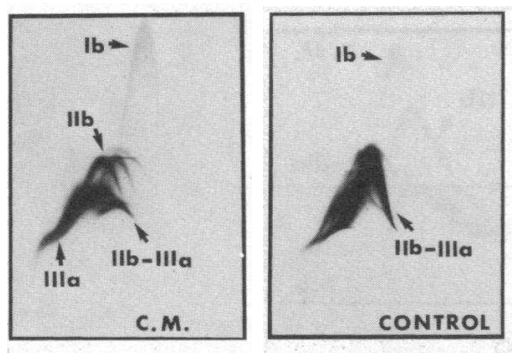

Figure 5. Analysis of the ${ }^{125}$ I-labeled surface glycoproteins of C.M. platelets by CIE. After radiolabeling, EDTAwashed platelets from C.M. and a control donor were solubilized with Triton X-100 and the soluble proteins $(100$

$\mu \mathrm{g})$ separated by a first-dimension electrophoresis in agarose. Seconddimension electrophoresis was performed across an intermediate gel without antibody into an upper agarose gel containing $750 \mu \mathrm{g} / \mathrm{cm}^{2}$ of the immunoglobulin fraction of a rabbit anti-human platelet serum. Immunoprecipitates containing ${ }^{125}$ I-labeled membrane glycoproteins were located by autoradiography. A decreased size of the precipitate containing GP IIb-IIIa on the C.M. platelet pattern is accompanied by the appearance of precipitates in the positions of dissociated GP IIb and GP IIIa. 
Further experiments were performed to confirm the identification of the precipitates highlighted on Fig. 5. This confirmation was achieved using Triton X-100 extracts of unlabeled platelets and ${ }^{125} \mathrm{I}$-labeled monoclonal antibodies in the intermediate gel. T10, which is specific for GP IIb-IIIa complexes (17), labeled only the residual precipitate present in the IIb-IIIa position on the C.M. platelet pattern (Fig. 6). AP-2, a different antibody with a similar specificity (16), behaved identically (not illustrated). In contrast, Tab, which recognizes dissociated GP IIb (17), labeled both the residual GP IIb-IIIa complexes in increased amounts and the precipitate in the position of dissociated GP IIb.

The above results suggested that either circulating C.M. platelets contained appreciable amounts of dissociated GP IIb and GP IIIa, or that complex dissociation was occurring during the experimental procedures leading to the CIE. Platelets were therefore isolated in the presence of divalent cations and Triton X-100 extracts analyzed by CIE. Fig. 7 shows that GP IIb-IIIa complexes were normally present in C.M. platelets isolated in this way. The additional precipitate located by Tab in Fig. 6 was no longer present. The GP IIb-IIIa complexes were also normally observed by CB-R staining.

The following experiments were performed to see if the GP IIb-IIIa complexes of C.M. platelets were more sensitive to divalent cation chelation in solution. Previous studies have shown that at $4^{\circ} \mathrm{C}$ and $\mathrm{pH} 8.7$, EDTA induces a slow dissociation of GP IIb-IIIa complexes in Triton X-100 extracts of normal platelets $(30,31)$. Fig. 8 illustrates the effect of a 1-h incubation with $5 \mathrm{mM}$ EDTA on GP IIb-IIIa complexes solubilized from control and C.M. platelets isolated in the presence of calcium. Whereas ${ }^{125} \mathrm{I}-\mathrm{Tab}$ detected only small amounts of dissociated GP IIb in the control platelet extracts, a complete dissociation
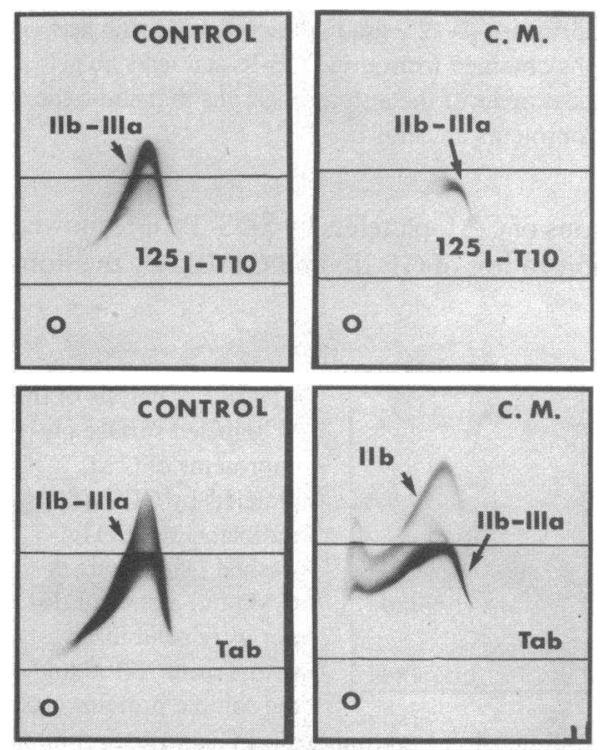

Figure 6. CIE of EDTA-washed platelets with ${ }^{125} \mathrm{I}-\mathrm{T} 10$ or ${ }^{125} \mathrm{I}-\mathrm{Tab}$ in the intermediate gel. Experimental details were as described in the legend to Fig. 5 with the exception that the intermediate gel contained 1 $\times 10^{6} \mathrm{cpm} / \mathrm{cm}^{2}{ }^{125} \mathrm{I}-\mathrm{T} 10$ or ${ }^{125} \mathrm{I}-\mathrm{Tab}$ and the initial solubilization of the platelets by Triton X-100 was performed in the presence of protease inhibitors (see Methods). Unlabeled platelets were used in these experiments. Precipitates containing radiolabel were identified by autoradiography.
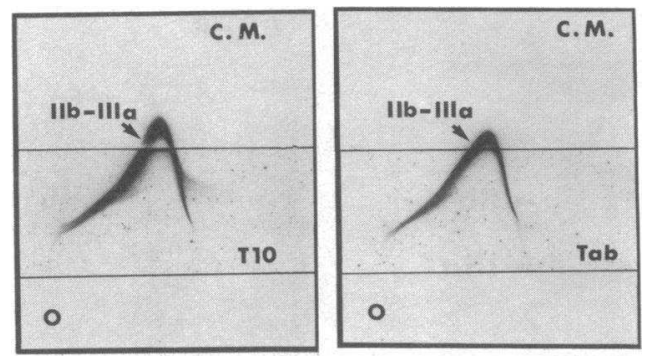

Figure 7. Detection of GP IIb-IIIa complexes in Triton X-100 extracts of C.M. platelets isolated in the presence of calcium. Experimental details for the CIE were as described in the Methods section and in the legend to Fig. 6. The intermediate gels contained ${ }^{125} \mathrm{I}-\mathrm{T} 10$ or ${ }^{125} \mathrm{I}-\mathrm{Tab}$ and the bound antibody was located by autoradiography.

of the GP IIb-IIIa complexes of C.M. platelets had occurred. No T10 or AP-2 binding precipitate remained (not illustrated). Other studies showed an approximate $80 \%$ dissociation of GP IIb-IIIa of C.M. platelets using $1 \mathrm{mM}$ EDTA for $1 \mathrm{~h}$ under these conditions, while no dissociation was observed with a mixture of $2 \mathrm{mM}$ EDTA and $5 \mathrm{mM} \mathrm{CaCl}$.

Monoclonal antibody binding to intact platelets. These studies were designed to illustrate whether EDTA-induced modifications of GP IIb-IIIa actually occurred in the surface membrane of C.M. platelets. Binding studies were performed using ${ }^{125} \mathrm{I}$-labeled T10, AP-2, or Tab and platelets that had been washed in the presence of divalent cations but were incubated in Tyrode- $\mathrm{Ca}^{2+}$ or Tyrode-EDTA for $30 \mathrm{~min}$ at room temperature before the addition of the antibody. The number of binding sites expressed by C.M. platelets for each antibody was calculated and Table II gives the results. In our binding assay, AP-2 binds to $39,400 \pm 5,800$ sites on control platelets and the number is unchanged after divalent cation chelation (see Table I and reference 31). As Table II shows, the binding of AP-2 to C.M. platelets in the presence of $\mathrm{Ca}^{2+}$ was in the normal range, yet after divalent cation chelation the binding was reduced to $<10 \%$ of this level. T10 behaved similarly to AP-2, with few binding sites expressed on C.M. platelets after EDTA treatment. In contrast, binding of Tab to C.M. platelets was identical with or without divalent cation chelation, showing that GP IIb remained exposed at the platelet surface in the presence of EDTA. The number of binding sites for T10 and Tab on control platelets under our conditions did not differ from those reported in Table $I$.

Binding of ${ }^{125}$ I-fibrinogen to GP IIb-IIIa complexes. It was crucial to know whether the GP IIb-IIIa complexes present in
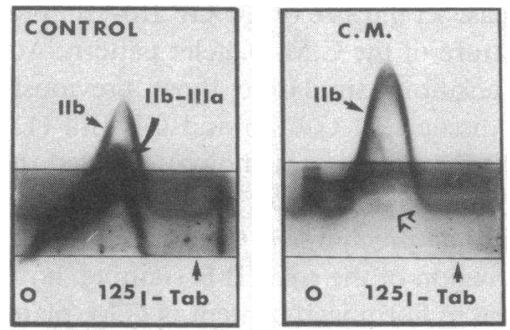

Figure 8. Dissociation of GP IIb-IIIa in Triton $\mathrm{X}-100$ by EDTA. $\mathrm{Ca}^{2+}$ washed normal human and C.M. platelets were solubilized with Triton $\mathrm{X}-100$ in the presence of protease inhibitors. Samples of the Triton $\mathrm{X}-100$-soluble proteins ( $6 \mathrm{mg}$ protein/ml) were incubated with $5 \mathrm{mM}$ EDTA for $1 \mathrm{~h}$ at $4^{\circ} \mathrm{C}$. CIE was performed with ${ }^{125} \mathrm{I}$-Tab in the intermediate gel and the bound antibody detected by autoradiography. The absence of IIb-IIIa complexes from the C.M. platelet pattern is highlighted (open arrow). 
Table II. Monoclonal Antibody Binding to C.M. Platelets

\begin{tabular}{|c|c|c|c|c|}
\hline \multirow[b]{2}{*}{ Antibody } & \multicolumn{2}{|c|}{$\begin{array}{l}\text { Binding in presence } \\
\text { of } \mathrm{Ca}^{2+}\end{array}$} & \multicolumn{2}{|c|}{$\begin{array}{l}\text { Binding in presence } \\
\text { of EDTA }\end{array}$} \\
\hline & & $\mathrm{kD}$ & & $\mathbf{k D}$ \\
\hline & No. of sites & $n M$ & No. of sites & $n M$ \\
\hline AP-2 & 38,900 & 1.88 & 2,540 & 0.41 \\
\hline $\mathrm{T} 10$ & 54,400 & 8.4 & 3,720 & 5.6 \\
\hline Tab & 43,900 & 4.5 & 52,000 & 1.8 \\
\hline
\end{tabular}

The binding of increasing concentrations of ${ }^{125} \mathrm{I}$-labeled antibodies to washed platelets together with the Scatchard analysis of the data was performed as detailed in the Methods section. Platelets in Tyrode- $\mathrm{Ca}^{2+}$ or Tyrode-EDTA were incubated at room temperature for $30 \mathrm{~min}$ before the assay.

C.M. platelets in a $\mathrm{Ca}^{2+}$-containing medium were capable of binding fibrinogen. Gogstad et al. (32) have shown how GP IIbIIIa complexes of normal platelets bind ${ }^{125}$ I-fibrinogen when the ligand is incubated with washed, unstained agarose gels after CIE. Fig. 9 illustrates how we have simplified this procedure by putting radiolabeled fibrinogen into the intermediate gel during the second dimension electrophoresis. A binding of ${ }^{125}$ I-fibrinogen to GP IIb-IIIa complexes of normal platelets is observed. The position of the GP IIb-IIIa precipitate was confirmed by performing parallel experiments with ${ }^{125} \mathrm{I}-\mathrm{AP}-2$ in the intermediate gel. In contrast, GP IIb-IIIa complexes in Triton X-100 extracts of $\mathrm{Ca}^{2+}$-washed C.M. platelets failed to bind fibrinogen. This suggests that a direct structural defect in the complexes may account for the lack of the aggregation response. As a precaution against the binding of ${ }^{125}$ I-fibrinogen to anti-fibrinogen antibodies trapped nonspecifically in the GP IIb-IIIa precipitate, these experiments were performed using a rabbit anti-human platelet antibody preparation that had been passed through a fibrinogen-Sepharose 4B affinity column. As would be expected, incubation of Triton X-100-soluble extracts of normal platelets with EDTA before the first dimension electrophoresis resulted in a loss in the fibrinogen-binding properties of the dissociated complex (not illustrated).
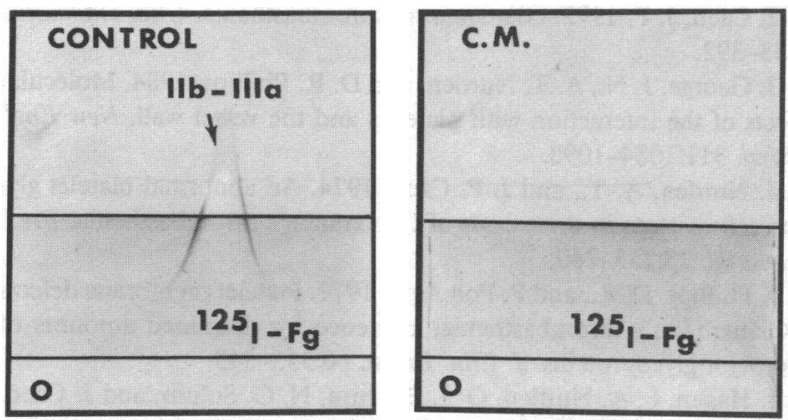

Figure 9. Binding of fibrinogen to GP IIb-IIIa complexes. $\mathrm{Ca}^{2+}$. washed normal human and C.M. platelets were solubilized with Triton X-100 in the presence of protease inhibitors. CIE was performed as described in the legend to Fig. 6 , with the exception that $1 \times 10^{6}$ $\mathrm{cpm} / \mathrm{cm}^{2}{ }^{125} \mathrm{I}$-fibrinogen $\left({ }^{125} \mathrm{I}-\mathrm{Fg}\right.$ ) was incorporated in the intermediate gel. Bound fibrinogen was revealed by autoradiography.

\section{Discussion}

Patient C.M. has platelets with functional abnormalities typical of Glanzmann's thrombasthenia (reviewed in reference 3). Platelet aggregation was defective and ADP failed to induce fibrinogen receptor expression on the platelet surface. A similar defect was observed with collagen, while thrombin failed to induce aggregation or clot retraction. Other platelet responses were essentially normal showing that the platelets were not refractory to the agonists. A weak dense granule secretion to low doses of collagen or thrombin was apparent, but this has also been observed in patients with type I thrombasthenia (33) and may be related to the absence of aggregation. This may explain why Coller et al. (34) were able to partially inhibit dense granule secretion with a monoclonal antibody to GP IIb-IIIa that completely blocked aggregation and fibrinogen binding.

Despite the platelet function defects, and a low level of platelet fibrinogen, no membrane glycoprotein abnormalities were apparent on analysis of either ${ }^{3} \mathrm{H}$ - or ${ }^{125} \mathrm{I}$-labeled C.M. platelets by one-dimensional SDS-PAGE, or high resolution two-dimensional acrylamide gel electrophoresis. In particular, the CB-R staining intensities, migration rates, and isoelectric points of GP IIb and GP IIIa were indistinguishable from those of control platelets. Quantitative studies have shown the presence of intermediate levels of GP IIb-IIIa in obligate carriers among family members of patients with type I Glanzmann's thrombasthenia (see references 3 and 8). Such results assert a link between the inheritance of the disorder and the GP abnormality. The implication is that newly described variants, such as patient C.M., possess structural defects in GP Ilb and/or GP IIIa or have other membrane abnormalities that prevent the normal functioning of GP IIb-IIIa complexes.

Evidence for a membrane defect in C.M. platelets first came from CIE, when analysis of platelets isolated in EDTA-containing buffers revealed a low content of GP IIb-IIIa complexes and precipitates in the positions of dissociated GP IIb and GP IIIa. This was unusual, because GP IIb and GP IIIa are normally solubilized from human platelets by nonionic detergent as the divalent cation-mediated heterodimer, and addition of EDTA (or EGTA) to the complexes in solution is required for dissociation of the individual glycoproteins $(13,14,18,30,35-37)$. Addition of EDTA to intact normal platelets at room temperature has little or no effect $(31,36)$, presumably because the divalent cations that mediate complex formation are inaccessible for chelation. One possible explanation for the low concentration of GP IIb-IIIa complexes in extracts of EDTA-washed C.M. platelets was that a structural defect prevented complex formation. This was excluded when it was found that C.M. platelets isolated in a calcium-containing buffer gave an abundant GP IIb-IIIa immunoprecipitate when analyzed by CIE and bound quantitatively normal amounts of the GP IIb-IIIa-dependent monoclonal antibodies. These findings also preclude the patient being considered heterozygous for classic thrombasthenia.

There is now overwhelming evidence that GP IIb-IIIa complexes are a prominent component of the surface membrane of circulating platelets. For example, Fitzgerald and Phillips (36) have examined the sedimentation of GP IIb and GP IIIa on sucrose gradients after lysis of ${ }^{125} \mathrm{I}$-labeled human platelets in Triton X-100 under conditions that stabilized both the complexed and dissociated forms of GP IIb and GP IIIa. Over $90 \%$ of the glycoproteins were present as the heterodimer. Using another approach, Shattil et al. (37) demonstrated the presence of 
the complex in detergent extracts of unstimulated platelets by electrophoresis on nondenaturing, polyacrylamide gradient gels. These studies underline the results that have been obtained for normal platelets using $\operatorname{CIE}(6,8,13,18,30-32)$. At room temperature, AP-2 binds similarly to normal platelets in the presence of divalent cations or with $\operatorname{EDTA}(16,31)$. However, the number of binding sites for T10 on normal platelets has been shown to fall to $\sim 50 \%$ of usual levels after divalent cation chelation with EDTA for $1 \mathrm{~h}$ at $22^{\circ} \mathrm{C}(17)$. In contrast, when these antibodies were incubated with C.M. platelets at room temperature, the number of binding sites fell to $<10 \%$ within $30 \mathrm{~min}$ of the addition of EDTA. Thus the epitopes for both AP-2 and T10 are extremely sensitive to divalent cation chelation in the surface membrane of C.M. platelets, which implies an abnormal structure or organization of the GP IIb-IIIa complexes in situ.

Brass and Shattil (38) have reported that the human platelet surface contains two classes of binding sites for extracellular $\mathrm{Ca}^{2+}$ that differ in their affinity. Their data obtained using normal and thrombasthenic platelets suggested that GP IIb and GP IIIa are the major $\mathrm{Ca}^{2+}$-binding glycoproteins on unstimulated platelets and that each complex contains two high and six low affinity binding sites for $\mathrm{Ca}^{2+}$. Peerschke and Zucker (39) had previously reported a decreased binding of calcium to thrombasthenic platelets. One explanation for our findings with C.M. platelets is that the GP IIb-IIIa complex is deficient in one or more $\mathrm{Ca}^{2+}$-binding sites. This would explain both the EDTAinduced loss of AP-2- and T10-binding to C.M. platelets, and the unusually rapid dissociation of the complexes in solution at $4^{\circ} \mathrm{C}$. Further studies using ${ }^{45} \mathrm{Ca}^{2+}$ are planned to test this possibility.

Recent studies by Pidard et al. (31) have shown that normal platelets treated with EDTA at $37^{\circ} \mathrm{C}$ lose their capacity to bind AP-2 due to a loss of antigenic determinants on GP IIb-IIIa. Similar temperature-dependent losses in GP IIb-IIIa antigenicity have been reported in binding studies with other monoclonal antibodies specific for the complex $(40,41)$. However, these effects of EDTA on normal platelets are only observed at $37^{\circ} \mathrm{C}$, whereas the GP IIb-IIIa complexes of C.M. platelets were modified at room temperature. At $37^{\circ} \mathrm{C}$, EDTA first dissociates GP IIb-IIIa in normal platelets. However, this dissociation is then followed by a re-association of the glycoproteins into high molecular weight complexes $(31,36,37)$. The observed changes are associated with a loss of fibrinogen receptor expression and include the appearance of a new cathodal-migrating precipitate in CIE that bound Tab but not AP-2 (31). These modifications should be clearly distinguished from those observed with C.M. platelets where precipitates in the positions of dissociated GP IIb or GP IIIa were exclusively observed.

Studies using CIE (32), an enzyme-linked immunoadsorbant assay (42), cross-linking reactions (43), or isolated GP IIb-IIIa complexes incorporated into liposomes (44), all point to GP IIb-IIIa being the fibrinogen receptor on normal human platelets. Fibrinogen binding to ADP-stimulated C.M. platelets did not occur despite the ability of GP IIb and GP IIIa to form complexes in these platelets. In normal human platelets the fibrinogen binding domain is exposed only after platelet activation. Thus, the defect in C.M. platelets may arise through either an abnormality in the mechanism of exposure of the fibrinogen-binding conformation on GP IIb-IIIa or be a result of a structural modification directly affecting the fibrinogen-binding determinant. Several studies have shown that a divalent cation-dependent interaction between fibrinogen and GP IIb-IIIa may be demon- strated after isolation of the complex and that this occurs in the absence of ADP $(32,42,44)$. Such a finding implies that some, at least, of the isolated complexes directly express the fibrinogenbinding site. We studied the interaction between fibrinogen and GP IIb-IIla complexes by incorporating ${ }^{125}$ I-fibrinogen into the intermediate gel during CIE. The GP IIb-IIIa complexes of $\mathrm{Ca}^{2+}$ washed C.M. platelets failed to bind fibrinogen, which strongly suggests the presence of a defect close to or influencing the fibrinogen-binding determinant on the complexes. Interestingly, as in type I thrombasthenia (see reference 3 ), the abnormality was associated with a severe decrease in the fibrinogen content of the $\alpha$-granules of the platelets.

Thus, the patient C.M. appears to represent a new subgroup of thrombasthenia where platelets contain unstable GP IIb-IIIa complexes unable to support fibrinogen binding. The abnormality may also extend to other adhesive proteins $(3,45)$, for preliminary results also suggest a defective binding of von Willebrand factor to ADP- and thrombin-stimulated platelets (C. Mazurier and A. T. Nurden, unpublished results). The abnormalities present in the platelets of the patient are responsible for a lifelong bleeding disorder. No such problems have been experienced by other family members while an examination of the platelets of both parents has failed to reveal defects of GP IIb-IIIa complex dissociation. It is possible therefore that the patient herself has been the subject of a gene mutation. However, some prudence must be exercised in such an interpretation for it is possible that purported heterozygotes for this type of variant may be difficult to distinguish using present technology. Meanwhile, further studies on the GP IIb-IIIa heterodimers of patients such as C.M. may help to define the functional site of this complex, which has a key role in the mechanism of platelet aggregation.

\section{Acknowledgments}

We thank Dr. James N. George (San Antonio, TX) for his critical review of the manuscript and F. Hoffmann-La Roche and Co. (Basle, Switzerland) for financial support.

\section{References}

1. Caen, J. P., P. A. Castaldi, J. C. Leclerc, S. Inceman, M. J. Larrieu, M. Probst, and J. Bernard. 1966. Congenital bleeding disorders with long bleeding time and normal platelet count. Am. J. Med. 41:4-26.

2. Caen, J. P. 1972. Glanzmann's thrombasthenia. Clin. Haematol. 1:383-392.

3. George, J. N., A. T. Nurden, and D. R. Phillips. 1984. Molecular defects of the interaction with platelets and the vessel wall. New Engl. J. Med. 311:1084-1098.

4. Nurden, A. T., and J. P. Caen. 1974. An abnormal platelet glycoprotein pattern in three cases of Glanzmann's thrombasthenia. Br. J. Haematol. 28:253-260.

5. Phillips, D. R., and P. Poh Agin. 1977. Platelet membrane defects in Glanzmann's thrombasthenia. Evidence for decreased amounts of two major glycoproteins. J. Clin. Invest. 60:535-545.

6. Hagen, I., A. Nurden, O. J. Bjerrum, N. O. Solum, and J. Caen. 1980. Immunochemical evidence for protein abnormalities in platelets from patients with Glanzmann's thrombasthenia and Bernard-Soulier syndrome. J. Clin. Invest. 65:722-731.

7. McGregor, J. L., K. J. Clemetson, E. James, A. Capitanio, T. Greenland, E. F. Lüscher, and M. Dechavanne. 1981. Glycoproteins of platelet membranes from Glanzmann's thrombasthenia. A comparison with normal using carbohydrate-specific or protein-specific labelling 
techniques and high resolution two dimensional gel electrophoresis. Eur. J. Biochem. 116:379-388.

8. Kunicki, T. J., D. Pidard, J.-P. Cazenave, A. T. Nurden, and J. P. Caen. 1981. Inheritance of the human platelet alloantigen, $P 1^{A 1}$, in type I Glanzmann's thrombasthenia. J. Clin. Invest. 67:717-724.

9. Mustard, J. F., R. L. Kinlough-Rathbone, M. A. Packham, D. W. Perry, E. J. Harfenist, and K. R. M. Pai. 1979. Comparison of fibrinogen association with normal and thrombasthenic platelets on exposure to ADP or chymotrypsin. Blood 54:987-993.

10. Bennett, J. S., and G. Villaire. 1979. Exposure of platelet fibrinogen receptors by ADP and epinephrine. J. Clin. Invest. 64:1393-1401.

11. Peerschke, E. I., M. B. Zucker, R. A. Grant, J. J. Egan, and M. M. Johnson. 1980. Correlation between fibrinogen binding to human platelets and platelet aggregability. Blood 55:841-847.

12. Lee, H., A. T. Nurden, A. Thomaidis, and J. P. Caen. 1981. Relationship between fibrinogen binding and the platelet glycoprotein deficiencies in Glanzmann's thrombasthenia type I and type II. Br. J. Haematol. 48:47-57.

13. Kunicki, T. J., D. Pidard, J. P. Rosa, and A. T.Nurden. 1981. The formation of $\mathrm{Ca}^{2+}$-dependent complexes of platelet membrane glycoproteins IIb and IIIa in solution as determined by crossed immunoelectrophoresis. Blood 58:268-278.

14. Jennings, L. K., and D. R. Phillips. 1982. Purification of glycoprotein IIb and IIIa from human platelet plasma membranes and characterization of a calcium-dependent glycoprotein IIb-IIIa complex. $J$. Biol. Chem. 257:10458-10466.

15. McGregor, J. L. 1986. Monoclonal Antibodies and Human Blood Platelets. Elsevier Science Publishing Co., Inc., Amsterdam. 1-328.

16. Pidard, D., R. R. Montgomery, J. S. Bennett, and T. J. Kunicki. 1983. Interaction of AP-2, a monoclonal antibody specific for the human platelet glycoprotein IIb-IIIa complex, with intact platelets. J. Biol. Chem. 258:12582-12586.

17. McEver, R. P., E. M. Bennett, and M. N. Martin. 1983. Identification of two structurally and functionally distinct sites on human platelet membrane glycoprotein IIb-IIIa using monoclonal antibodies. J. Biol. Chem. 258:5269-5275.

18. Howard, L., S. Shulman, S. Sadanandan, and S. Karpatkin. 1982. Crossed immunoelectrophoresis of human platelet membranes. The major antigen consists of a complex of glycoproteins, GP IIb and GP IIIa, held together by $\mathrm{Ca}^{2+}$ and missing in Glanzmann's thrombasthenia. J. Biol. Chem. 257:8331-8336.

19. Kunicki, T. J., A. T. Nurden, D. Pidard, N. R. Russell, and J. P. Caen. 1981. Characterization of human platelet glycoprotein antigens giving rise to individual immunoprecipitates in crossed immunoelectrophoresis. Blood 58:1190-1197.

20. Lightsey, A. L., E. F. Plow, R. McMillan, and M. H. Ginsberg. 1981. Glanzmann's thrombasthenia in the absence of GP IIb and GP IIIa deficiency. Blood 58:199a. (Abstr.)

21. Caen, J. P., J. P. Rosa, B. Boizard, and A. T. Nurden. 1983. Thrombasthenia Paris I variant, a model for the study of the platelet glycoprotein (GP) IIb-IIla complex. Blood 62:25a. (Abstr.)

22. Kunicki, T. J., D. Pidard, R. R. Montgomery, N. Abramson, and R. H. Aster. 1982. Familial study of a variant form of Glanzmann's thrombasthenia. Circulation 66:297. (Abstr.)

23. Fitzgerald, L. A., J. Chediak, L. K. Jennings, S. V. Strother, and D. R. Phillips. 1985. Identification of molecular variants of Glanzmann's thrombasthenia. Blood 66(Suppl. 1):289a. (Abstr.)

24. Patscheke, H. 1981. Shape and functional properties of human platelets washed with acid citrate. Haemostasis 10:14-27.

25. Legrand, C., V. Dubernard, and A. T. Nurden. 1985. Characteristics of collagen-induced fibrinogen binding to human platelets. Biochim. Biophys. Acta 812:802-810.

26. Legrand, C., and A. T. Nurden. 1985. Studies on platelets of patients with inherited platelet disorders suggest that collagen-induced fibrinogen binding to membrane receptors requires secreted ADP but not released $\alpha$-granule proteins. Thrombos. Haemostasis. 54:603-606.

27. Nurden, A. T., D. Dupuis, T. J. Kunicki, and J. P. Caen. 1981.
Analysis of the glycoprotein and protein composition of Bernard-Soulier platelets by single and two-dimensional sodium dodecyl sulfate-polyacrylamide gel electrophoresis. J. Clin. Invest. 67:1431-1440.

28. Nurden, A. T., D. Dupuis, D. Pidard, N. Kieffer, T. J. Kunicki, and J.-P. Cartron. 1982. Surface modifications in the platelets of a patient with $\alpha-N$-acetyl D-galactosamine residues, the Tn-syndrome. J. Clin. Invest. 70:1281-1291.

29. Ames, G. F., and K. Nikaido. 1976. Two dimensional gel electrophoresis of membrane proteins. Biochemistry 15:616-623.

30. Rosa, J. P., N. Kieffer, D. Didry, D. Pidard, T. J. Kunicki, and A. T. Nurden. 1984. The human platelet membrane glycoprotein complex GP IIb-IIIa expresses antigenic sites not exposed on the dissociated glycoproteins. Blood 64:1246-1253.

31. Pidard, D., D. Didry, T. J. Kunicki, and A. T. Nurden. 1986. Temperature-dependent effects of EDTA on the membrane glycoprotein IIb-IIIa complex and platelet aggregability. Blood 67:604-611.

32. Gogstad, G. O., F. Brosstad, M-B. Krutnes, I. Hagen, and N. O. Solum. 1982. Fibrinogen-binding properties of the human platelet glycoprotein IIb-IIIa complex: a study using crossed-radioimmunoelectrophoresis. Blood 60:663-671.

33. Malmsten, C., H. Kindahl, B. Samuelsson, S. Levy-Toledano, G. Tobelem, and J. P. Caen. 1977. Thromboxane synthesis and the platelet release reaction in Bernard-Soulier syndrome, Glanzmann's thrombasthenia and Hermansky-Pudlak syndrome. Br. J. Haematol. 35: 511-520.

34. Coller, B. S., E. I. Peerschke, L. E. Scudder, and C. A. Sullivan. 1983. A murine monoclonal antibody that completely blocks the binding of fibrinogen to platelets produces a thrombasthenic-like state in normal platelets and binds to glycoproteins IIb and/or IIIa. J. Clin. Invest. 72: 325-338.

35. Carrell, N. A., L. A. Fitzgerald, B. Steiner, H. P. Erickson, and D. R. Phillips. 1985. Structure of human platelet membrane glycoproteins IIb and IIIa as determined by electron microscopy. J. Biol. Chem. 260: 1743-1749.

36. Fitzgerald, L. A., and D. R. Phillips. 1985. Calcium regulation of the platelet membrane glycoprotein IIb-IIIa complex. J. Biol. Chem. 260:11366-11374.

37. Shattil, S. J., L. F. Brass, J. S. Bennett, and P. Pandhi. 1985. Biochemical and functional consequences of dissociation of the platelet membrane glycoprotein IIb-IIIa complex. Blood 66:92-98.

38. Brass, L. F., and S. J. Shattil. 1984. Identification and function of the high affinity binding sites for $\mathrm{Ca}^{2+}$ on the surface of platelets. $J$. Clin. Invest. 73:626-632.

39. Peerschke, E. I., R. A. Grant, and M. B. Zucker. 1980. Decreased association of ${ }^{45} \mathrm{calcium}$ with platelets unable to aggregate due to thrombasthenia or prolonged calcium deprivation. Br. J. Haematol. 46:247256.

40. Brass, L. F., S. J. Shattil, T. J. Kunicki, and J. S. Bennett. 1985. Effect of calcium on the stability of the platelet membrane glycoprotein IIb-IIIa complex. J. Biol. Chem. 260:7875-7881.

41. Coller, B. S., E. I. Peerschke, U. Seligsohn, L. E. Scudder, A. T. Nurden, and J. P. Rosa. 1986. Studies on the binding of an alloimmune and two murine monoclonal antibodies to the platelet glycoprotein IIbIIIa complex receptor. J. Lab. Clin. Med. 107:384-392.

42. Nachman, R. L., and L. L. K. Leung. 1982. Complex formation of platelet membrane glycoproteins IIb and IIIa with fibrinogen. J. Clin. Invest. 69:263-269.

43. Bennett, J. S., G. Vilaire, and D. B. Cines. 1982. Identification of the fibrinogen receptor on human platelets by photoaffinity labeling. J. Biol. Chem. 257:8049-8054.

44. Parise, L. V., and D. R. Phillips. 1985. Reconstitution of the purified fibrinogen receptor. Fibrinogen binding properties of the glycoprotein IIb-IIIa complex. J. Biol. Chem. 260:10698-10707.

45. Plow, E. F., M. H. Ginsberg, and G. A. Marguerie. 1986. Expression and function of adhesive proteins on the platelet surface. In Biochemistry of Platelets. D. R. Phillips and M. A. Shulman, editors. Academic Press, Inc., New York. 225-256. 